\title{
Letter search through words and nonwords: The effect of fixed, absent, or mutilated targets
}

\author{
LESTER E. KRUEGER \\ The Ohio State University, Columbus, Ohio 43210 \\ and \\ MADELIN E. WEISS \\ Fordham University, New York, New York 10007
}

\begin{abstract}
The present study attempted to eliminate the word superiority effect found in letter search by holding the target letter fixed across trials. The expectation was that the target would thereby become so familiar and salient that the subject would "see" only that letter during search. Even with the target-letter held fixed (Experiment I), however, search was still faster through words than through nonwords, indicating that nontarget letters had been "seen" as well. Search also remained faster through words than through nonwords when the number of exposures to the target was further increased by having the subject search for the absence rather than the presence of the target letter (Experiment III). In line with the notion of "proofreader's errors," however, search became relatively more accurate on nonwords than on words when it required detection of the "mutilation" produced by substituting an $\mathrm{F}$ for an $\mathrm{E}$, e.g., BASKFT, BAKFRY (Experiment IV).
\end{abstract}

Can visual search become so highly tuned and automated that virtually everything, except the target itself, is excluded from further consideration at a very low level of processing? Practice seemingly can do wonders for the search process. Neisser's (1963, 1964; Neisser. Novick, \& Lazar, 1963) well-practiced subjects reported that they did not even "see" nontarget letters during search for a target letter. Neisser proposed a hierarchical model in which nontarget letters are analyzed only deeply enough so that they can be discarded, and thus "throughout the scan nothing takes place at the level of letter identification until the target letter appears" (Neisser, 1964, p. 97).

On the other hand, Krueger (1970) found letter search to be faster through words than through nonwords (scrambled collections of letters), indicating that subjects do, indeed, "see" nontarget letters. Krueger's procedure differed from that of Neisser, however, in that the target changed on every trial, rather than remaining fixed. Keeping the target letter fixed ought to provide a greater opportunity for the subject to develop ways to focus on the target letter during search and thus exclude nontarget letters from higher level processing. When Gibson, Tenney, Barron, and Zaslow (1972) used a fixed target, in fact, they found no difference in speed of letter search

This study was supported by NIH Grant HD04869. The authors would like to thank Margaret A. Brown and Richard A. Cohen for assistance in collecting and tabulating the data. Requests for reprints should be sent to Lester E. Krueger, Human Performance Center, Ohio State University, 404-B West 17th Avenue, Columbus, Ohio 43210. through orthographically well-structured letter strings (e.g.. GLURK) and search through poorly structured ones (e.g.. RKUGL). Several other factors, however, might explain the negative findings of Gibson et al. most notably their use of a less sensitive, between-subjects experimental design. The present study tested whether the use of a fixed target also would eliminate the word superiority effect when Krueger's (1970) basic procedure was employed.

Experiment I held the target letter fixed as the letter E. To evaluate the results of Experiment I, the target letter was varied across trials in Experiment II, with the letters $E, K$, and $S$ serving as target letters. These three letters constitute a representative set of letters, since they include both vowel $(E)$ and consonant $(K, S)$ letters, high-frequency $(E, S)$ and low-frequency $(K)$ letters, and curved $(S)$ and noncurved ( $E, K)$ letters. Experiment III had the same basic design as Experiment I, but reversed the task, so that instead of searching for the presence of an $E$ in an item on a list that contained at most one $E$, the subject searched for the absence of an $E$ in an item on a list that contained many instances of $E$. The subject thus was exposed to $E$ much more frequently in Experiment III, and this ought to have increased any tendency to focus attention exclusively on the target letter.

Experiment IV extends Experiment III to address a different issue, that of "proofreader's errors," and will be discussed further below. Another subsidiary issue is addressed in Experiment I. where some subjects searched through horizontally arrayed items and others through vertically arrayed items. The 
question here was whether the horizontal arrangement would induce the subjects to rely more on well-learned reading skills and thus to make fuller use of their familiarity with words. Yet another subsidiary issue was whether the advantage for words over nonwords in letter search is based on visual-spatial rather than verbal processing. In Experiments I to III, accordingly, the subjects received a card-rotations test after the visual search session, so that their performance on both tasks could be correlated. The ability to deal with rotated figures is assumed here to reflect a general visual-spatial aptitude, since it has been found to correlate with the ability to detect embedded figures (Hock, Gordon, \& Marcus. 1974), and with the ability to solve problems based upon the manipulation of blocks, and with the degree of self-reported imagery (Snyder, 1972).

\section{EXPERIMENTS I, II, AND III}

\begin{abstract}
Method
Subjects. Eighty City College of New York undergraduates served as paid subjects. There were 20 in the horizontal condition and 20 in the vertical condition of Experiment I, 20 in Experiment II, and 20 in Experiment III. All subjects had 20/30 vision (corrected) or better.
\end{abstract}

Apparatus. Search displays were presented in a light-tight wooden box containing a semitransparent (one-way) mirror (12 15 in.); the subject could see into the box whenever four $40-\mathrm{W}$ lamps inside were lit. On each trial, the experimenter first slid a plank containing the $81 / 2 \times 11$ in. stimulus sheet into the box. and then closed a switch which illuminated the lamps and started a Standard Electric. Model S-1 timer (calibrated to $.01 \mathrm{sec}$ ). The subject's response extinguished the lamps and stopped the timer.

Stimulus materials. Each display contained a list of 30 six-letter items. The items were sampled from a 140 -item pool, containing either common words, rare words, third-order pseudowords. or one of the sets of nonwords which had been formed by randomly permuting the letters within each letter position for each of the three types of words. The third-order pseudowords were constructed so as to reflect the trigram structure of English. (For further details on the 140-item pools, see Krueger, 1970.) Sampling was without replacement, so that no item appeared twice on a given display.

Half of the displays contained a critical item (i.e., an item with target present in Experiments I and II. or an item with the target absent in Experiment III), and the other half contained no critical item. The location of the critical item was varied widely across displays. There were too many different locations to be able to assign one display from each condition to each location. Instead, a representative set of Iocations was assigned to each condition so that the average position of the critical item, when it appeared, was the 12 th item on the list. In Experiments I and III, for common-word displays as well as the displays for their corresponding nonwords, the critical item occurred once each as Item $1,8,11,19$, and 21 ; for rare words and their corresponding nonwords, 5, 6, 9, 15, and 25; for third-order pseudowords and their corresponding nonwords, 3 . 4. 13. 17. and 23. In Experiment II, the target set was enlarged to include $E$. $K$, and $S$, but only common words and their corresponding nonwords were presented in the displays. The target letter $E$, when it did appear, was in Item $1,8,11,19$, or 21 . The target letter $K$. when it appeared. was in Item $5,6,9,15$, or 25 . The target letter $S$, when it appeared, was in Item 3, 4, 13, 17, or 23. During practice in Experiment II, the subject was shown examples of the targets $\mathrm{E}, \mathrm{K}$, and $\mathrm{S}$, and during regular trials, the subject was verbally informed immediately before each trial whether to search for an E. K, or S.
Five blocks of 12 displays each were devised, with each block containing one critical-item-present display and one critical-itemabsent display (both chosen randomly) for each of the six types of displays (common words, rare words, third-order pseudowords, and the three types of corresponding nonwords in Experiments $I$ and III; common words and the corresponding nonwords, for each of the three target letters in Experiment II). The 12 displays within each block were randomly permuted and presented in the resulting order to half of the subjects and in the reverse order to the other half. The order of the five blocks was varied over subjects, so that each block occurred an equal number of times as Block 1, 2, 3. 4. and 5 . In addition to the 60 regular displays, there were three practice displays (one contained words. two contained nonwords: one contained a target letter, two did not).

In the vertical condition of Experiment I, the six-letter items were typed in a single 30-row column, double-spaced, centered on an $8 \frac{1}{2} \times 11$ in. sheet. In the horizontal condition of Experiment I, the exact same six-letter items were typed six to a row, with two blank spaces between items. and formed five triple-spaced rows. centered towards the top of an $81 / 2 \times 11$ in. sheet. All displays in Experiments II and III were arrayed vertically. The items were typed in all capitals, in 10-pitch IBM Courier 72.

Procedure. The subject was instructed to search for the critical item (defined by the presence of an uppercase $E$ in Experiment $I$, the absence of an $E$ in Experiment III, or the presence of the uppercase letter, $E, K$, or $S$, as specified for that trial, in Experiment II) as quickly as possible, but not at the expense of accuracy, starting at the top and proceeding down (vertical condition), or starting at the upper left and proceeding left to right and then top to bottom (horizontal condition). The subject was told to press the right-hand button ("yes") as soon as he found the critical item, or, if he failed to find it, to press the left-hand button ("no") immediately upon coming to the end of the list, without back-tracking to double-check the absence. The subjects were offered a $25 \mathrm{c}$ bonus if their search speed fell in the top quartile for the experiment, and if their errors were kept below $5 \%$.

After searching through the three practice displays and 60 regular displays, the card-rotations test (Educational Testing Service) was administered to the subject. A series of problems was presented, each showing one figure on the left and eight figures on the right. The subject had to mark each of the eight figures. which appeared in various rotations, as to whether it was identical to the figure at the left. disregarding any change in orientation. The subjects had $8 \mathrm{~min}$ to complete the test. which contained 28 problems, each with eight items. and thus a total of 224 possible answers. In order that both the quality and quantity of performance be reflected in the response measure, items incorrectly marked were subtracted from those correctly marked to give the "net correct" score used here.

Data analysis. All error trials were removed before the search time data were analyzed. To ensure that the remaining data were comparable, when an error was removed from the word set for a particular condition, the trial on which the target was located in the same item position on the corresponding nonword set also was removed, and vice versa.

\section{Results}

As shown in Table 1, in Experiment $\mathrm{I}$, where the target remained fixed as $E$, words were searched significantly faster than nonwords, $F(1,38)=8.13$, $\mathrm{p}<.01 ; \mathrm{MS}_{\mathrm{e}}=1,615.02$; no other main effect or interaction on search time was significant. Error rate was slightly, but not significantly, higher for words than nonwords, $F<1$, but was significantly higher for horizontal than vertical displays, $F(1,38)=6.93$. $\mathrm{p}<.025, \mathrm{MS}_{\mathrm{e}}=138.55$. Word set also had a significant effect, $\mathrm{F}(2,76)=4.05, \mathrm{p}<.025, \mathrm{MS}_{\mathrm{e}}=$ 56.85; the error rate was lower for common words and their nonwords than for rare words and their 
Table 1

Mean Search Time Per Item (in Milliseconds) and Mean Error Rate (in Parentheses) in Experiment I

\begin{tabular}{|c|c|c|c|}
\hline Item Type & Common & $\begin{array}{l}\text { Word Set } \\
\text { Rare }\end{array}$ & Third Order \\
\hline \multicolumn{4}{|c|}{ Horizontal Displays } \\
\hline $\begin{array}{l}\text { Words } \\
\text { Nonwords }\end{array}$ & $\begin{array}{l}384(7.0 \%) \\
405(8.5 \%)\end{array}$ & $\begin{array}{l}396(10.0 \%) \\
406(8.0 \%)\end{array}$ & $\begin{array}{ll}407 & (10.0 \%) \\
406 & (11.0 \%)\end{array}$ \\
\hline $\begin{array}{l}\text { Time Savings } \\
\text { for Words }\end{array}$ & +21 & +10 & -1 \\
\hline Vertical Displays & & & \\
\hline $\begin{array}{l}\text { Words } \\
\text { Nonwords }\end{array}$ & $\begin{array}{ll}405 & (4.0 \%) \\
427 & (1.0 \%)\end{array}$ & $\begin{array}{l}411(7.0 \%) \\
430(7.5 \%)\end{array}$ & $\begin{array}{l}404(5.5 \%) \\
423(5.5 \%)\end{array}$ \\
\hline $\begin{array}{l}\text { Time Savings } \\
\text { for Words }\end{array}$ & +22 & +19 & +19 \\
\hline
\end{tabular}

Table 2

Mean Search Time Per Item (in Milliseconds) and Mean Error Rate (in Parentheses) in Experiment II

\begin{tabular}{lcccc}
\hline & \multicolumn{4}{c}{ Target Letter } \\
\multicolumn{1}{c}{ Item Type } & $\mathrm{E}$ & $\mathrm{K}$ & $\mathrm{S}$ \\
\hline Words & $450(11.0 \%)$ & $479(11.0 \%)$ & $411(5.0 \%)$ \\
Nonwords & $498(4.5 \%)$ & $557(13.5 \%)$ & $469(7.0 \%)$ \\
$\begin{array}{l}\text { Time Savings } \\
\text { for Words }\end{array}$ & +48 & +78 & +58 \\
\hline
\end{tabular}

nonwords, or for third-order pseudowords and their nonwords.

As shown in Table 2, in Experiment II, where the target on a given trial was $\mathrm{E}, \mathrm{K}$, or $\mathrm{S}$, words again were significantly faster than nonwords, $F(1,19)=$ 8.27, $\mathrm{p}<.01, \mathrm{MS}_{\mathrm{e}}=13,771.36$, but insignificantly higher on error rate, $F<1$. The different target letters differed significantly, both on search time, $\mathrm{F}(2.38)=22.01, \mathrm{p}<.001, \mathrm{MS}_{\mathrm{e}}=2,791.89$, and error rate, $F(2.38)=4.31, \mathrm{p}<.025, \mathrm{MS}_{\mathrm{e}}=96.54$. Search was fastest and most accurate with $S$ as the target letter. nearly as fast and accurate with $\mathrm{E}$, but much slower and less accurate with $\mathbf{K}$. The Target Letter by Word-Nonword interaction was not significant on search time, $F(2,38)=2.49, p<.10$, $\mathrm{MS}_{\mathrm{e}}=902.74$, but was significant on error rate, $F(2,38)=3.49, p<.05, M_{e}=73.37$. The error rate was higher for words than nonwords for the target letter $\mathrm{E}$, but lower for words than nonwords for $\mathrm{S}$ and $\mathrm{K}$.

Though the subjects in Experiment I searched significantly faster through words than nonwords, the time savings for words were smaller than those found in Experiment II and other studies. Using a similar procedure, but changing the target on each trial, Krueger, Keen, and Rublevich (1974; Experiment II) found a 49-msec time savings per item for common words, which was significantly greater than the 22-msec time savings for common words found in the present Experiment $\mathrm{I}, \mathrm{t}(78)=2.15, \mathrm{p}<.05$. The 48-msec time savings for common words with target letter $\mathrm{E}$ in the present Experiment II, however, was not significantly larger than the $23-\mathrm{msec}$ time savings for common words presented in a vertical arrangement in Experiment I. The lack of significance in the latter case is due to an inexplicable increase in the variability of the time-savings data from the present Experiment II $(S D=103)$, as compared with the present Experiment I $(S D=47)$ and Krueger et al.'s Experiment II $(S D=65)$.

Experiment III differed from the vertical condition of Experiment I only in that the subjects searched for the absence rather than the presence of an $E$. Experiment III produced a significantly slower search than Experiment l. 645 vs. $417 \mathrm{msec}$ per item. $F(1,38)=29.16, p<.001, \mathrm{MS}_{\mathrm{e}}=107,271.30$, an insignificantly lower error rate, $4.3 \%$ vs. $5.1 \%$, and an insignificantly larger time savings for words, 22 vs. 20 msec. Moreover, as shown in Table 3, in Experiment III, the subjects searched significantly faster through word than through nonword lists, $\mathrm{F}(1,19)=11.37, \mathrm{p}<.01, \mathrm{MS}_{\mathrm{e}}=1,253.51$, and had an insignificantly higher error rate on word lists, $F<1$.

In order to examine more fully the effect of practice. search time also was analyzed by trial block. Only displays in which the critical item was absent, and the subject thus searched through all 30 items, were included, because fewer errors were made on such trials and the data could be more readily compared across blocks. The data for each experiment are shown in Table 4 . In no case did the time savings for words decline significantly over trial blocks. In Experiment $I$, the significant HorizontalVertical by Block interaction, $F(4,152)=3.14$, $\mathrm{p}<.025, \mathrm{MS}_{\mathrm{e}}=6,948.05$, reflected the fact that search time declined to a greater extent across blocks for the horizontal than for the vertical condition.

On the card-rotations test. the subjects could achieve a maximum score of 224. In Experiment I, the net-correct score, which averaged 123 (range: 9 to 214; $S D=48$ ), correlated significantly with average search time per item, $r=-.34, p<.05$, but not with time savings per item for words, $r=-.19$, or average error rate, $r=-.08$. In Experiment II, the net-correct score, which averaged 106 (range: 34 to 148; SD $=33$ ), did not correlate significantly with either mean search time per item, $r=+.02$, time savings for words, $r=+.03$, or mean error rate, $r=-.13$. In

Table 3

Mean Search Time Per Item (in Milliseconds) and Mean Error Rate (in Parentheses) in Experiment III

\begin{tabular}{lcccc}
\hline \multicolumn{1}{c}{ Item Type } & Common & $\begin{array}{c}\text { Word Set } \\
\text { Rare }\end{array}$ & Third Order \\
\hline Words & $621(5.0 \%)$ & $632(4.0 \%)$ & $649(5.5 \%)$ \\
Nonwords & $656(4.0 \%)$ & $641(2.5 \%)$ & $670(4.5 \%)$ \\
$\begin{array}{l}\text { Time Savings } \\
\text { for Words }\end{array}$ & +35 & +9 & +21 \\
\hline
\end{tabular}


Table 4

Mean Search Time Per Item (in Milliseconds) for Displays With the Critical Item Absent, by Trial Block

\begin{tabular}{|c|c|c|c|}
\hline Block & Words & Nonwords & $\begin{array}{l}\text { Time Savings } \\
\text { for Words }\end{array}$ \\
\hline \multicolumn{4}{|c|}{ Experiment I: Horizontal Displays } \\
\hline 1 & 402 & 420 & +18 \\
\hline 2 & 384 & 395 & +11 \\
\hline 3 & 385 & 390 & +5 \\
\hline 4 & 360 & 375 & +15 \\
\hline 5 & 357 & 359 & +2 \\
\hline \multicolumn{4}{|c|}{ Experiment I: Vertical Displays } \\
\hline 1 & 389 & 400 & +11 \\
\hline 2 & 406 & 422 & +16 \\
\hline 3 & 386 & 418 & +32 \\
\hline 4 & 384 & 407 & +23 \\
\hline 5 & 379 & 404 & +25 \\
\hline \multicolumn{4}{|c|}{ Experiment II } \\
\hline 1 & 415 & 457 & +42 \\
\hline 2 & 441 & 497 & +56 \\
\hline 3 & 445 & 490 & +45 \\
\hline 4 & 452 & 525 & +73 \\
\hline 5 & 430 & 500 & +70 \\
\hline \multicolumn{4}{|c|}{ Experiment III } \\
\hline 1 & 633 & 668 & +35 \\
\hline 2 & 629 & 644 & +15 \\
\hline 3 & 607 & 624 & +17 \\
\hline 4 & 595 & 616 & +21 \\
\hline 5 & 596 & 614 & +18 \\
\hline \multicolumn{4}{|c|}{ Experiment IV } \\
\hline 1 & 554 & 607 & +53 \\
\hline 2 & 531 & 602 & +71 \\
\hline 3 & 521 & 595 & +74 \\
\hline 4 & 516 & 585 & +69 \\
\hline 5 & 503 & 583 & +80 \\
\hline
\end{tabular}

Experiment III, the net-correct score, which averaged 105 (range: 29 to $190 ; \mathrm{SD}=54$ ), correlated significantly with mean search time per item, $r=$ $-.67, \mathrm{p}<.01$, but not with time savings for words, $\mathrm{r}$ $=-.10$, or mean error rate, $r=-.22$. To test for a nonlinear relationship, a median split was made; the 39 subjects in Experiment $I$ who took the card rotations test were divided into 20 low-scoring subjects and 19 high-scoring subjects, and similar splits into groups of 10 low-scoring and 10 high-scoring subjects were made in Experiments II and III. There was no significant differences between low scorers and high scorers on any of the letter-search measures, except that in Experiment III the 10 low-scoring subjects had a significantly longer search time per item $(716 \mathrm{msec}$, $\mathrm{SD}=109)$ than the 10 high-scoring subjects $(573 \mathrm{msec}, \mathrm{SD}=119), \mathrm{t}(18)=2.40, \mathrm{p}<.05$.

\section{Discussion}

The present evidence indicates some reduction in the time savings for words (vs. nonwords) in letter search when the target letter is held fixed, as in Experiment I, rather than being allowed to vary, as in Experiment II and other studies. The reduction must have occurred quite early in the session, though, because the time savings for words showed little change over trial blocks. It would seem, then, that search does become somewhat more automated, with nontarget letters being more readily excluded from consideration, when the target letter is not varied.

More important, however, search was yet faster through words than through nonwords even with the target letter held fixed. Moreover, the advantage for words was not reduced further by greatly increasing the number of exposures to the target letter in Experiment III, where subjects searched for the absence rather than presence of the fixed target letter. The first author had felt quite confident that this procedure would finally eliminate the advantage for words in letter search; in pilot trials, it seemed simply too easy just to zig-zag down a virtual columns of Es, ignoring all nontarget letters, until the absence of an E was encountered. Neisser (1963) reported a related phenomenon with two-letter items; in looking for the absence of a $Z$, the subjects simply followed the column of Zs, which switched haphazardly from left to right. The results of Experiment III thus demonstrate again the robustness of the word superiority effect in letter search. Search was much slower in Experiment III, with the subjects having to verify the presence of an $E$ in every item, but attention was not so strongly riveted upon the target Es that the familiar context of the words in which the Es were embedded could not be gleaned. The success in finding a word superiority effect in Experiment III emboldened us to test in Experiment IV whether "proofreader's errors" were a myth, that a word as a familiar schema revealed more readily not only its component letters but also its misspellings as well.

The seeming failure to exclude nontarget letters at a low level of processing, even with target letter held fixed, may, of course, be due to choice rather than necessity. The subjects may simply have decided that attending to the nontarget letters would increase the search rate, as indeed occurred with words. Furthermore, the higher error rate on words (vs. nonwords) in Experiments I, II, and III, though nonsignificant, does suggest that at least part of the faster search through words ought to be dismissed as due to a speed-accuracy tradeoff rather than to faster information processing. A slight difference on errors can often produce a large difference in response time (Pachella, 1974). A speed-accuracy tradeoff cannot account for all instances of the word superiority effect in letter search, however, because the overall error rate is slightly, but reliably, lower for words than nonwords in studies in which the target letter is changed on every trial and many letters are used as targets (Krueger, 1970). As we shall see, the error data in Experiment IV again indicate that, with the target condition fixed, subjects increase their speed of search through words to a greater extent than they ought to. It also should be noted that Neisser practiced his subjects for many days, and it is 
conceivable that with the target letter held fixed over many sessions, the advantage for words in letter search would finally disappear.

How, then, are the negative findings of Gibson et al., who held the target letter fixed as an $\mathbf{N}$ in a single session, to be explained. Most likely, Gibson et al. failed to find significantly faster letter search through more familiar letter sequences because they sinply used a less sensitive, between-subjects experimental design. To simulate the effect of a change from a within-subjects to a between-subjects design in the present study, the 40 subjects in Experiment I were divided into two groups, and each group was treated as though it had provided data on only one condition, either words or nonwords. With the even-numbered subjects assigned to words, and the odd-numbered subjects to nonwords, search time per item was considerably shorter for words than nonwords. 371 vs. $455 \mathrm{msec}$, and this difference would have been significant, $F(1,36)=5.12, p<.05$, $\mathrm{MS}_{\mathrm{e}}=40.634 .03$. With the reverse subject assignment (i.e.. even-numbered subjects to nonwords, odd-numbered to words), however, the results reversed, with search time now being much faster for nonwords $(377 \mathrm{msec})$ than words $(431 \mathrm{msec})$. though this difference would not have been significant. $\mathrm{F}(1.36)=2.38$, n.s., $\mathrm{MS}_{\mathrm{e}}=$ 36.394.55. Evidently, the even-numbered subjects happened to be much faster in general than the odd-numbered subjects. Since subjects thus show considerable variability on general search time, it is quite conceivable that Gibson et al. failed to find faster letter search through more familiar sequences simply because the subjects who saw the familiar sequences happened to be their slower subjects.

As to the results of the card-rotations test, the correlations between performance on that test and on letter search were generally low and insignificant. There was a general tendency for the card-rotations test score to correlate negatively with the search factors, so that a high-scoring (and presumably high-spatial) subject tended to have a shorter search time. smaller time savings for words, and smaller error rate, but only the correlations with mean search time in Experiments I and III were significant. The present results represent yet another failure to pinpoint the specific abilities that enable subjects to exploit their familiarity with words to speed letter search. Krueger, Keen, and Rublevich (1974), similarly, found no difference between good readers and poor readers in the advantage for words over nonwords in letter search, though again there was an overall tendency for better readers to have shorter search times.

Finally, the present results are somewhat surprising in that they showed no difference on time savings for words between horizontal and vertical displays (Experiment I). A larger effect had been anticipated for the rorizontal display.

\section{EXPERIMENT IV}

Experiment IV examined the notion of "proofreader's errors," that is the common belief that misspellings are more difficult to detect in more familiar words, presumably due to incomplete processing of, or inattention to, orthographic features. Experiment III required the subjects to search for the absence of an E, but the target-absent item on word lists was yet a word, and thus provided a familiar schema characterized by the absence of an E. In Experiment IV. on the other hand, the critical item on word lists was not a word; an E-bearing word was "mutilated" by simply changing its E to an F, so that a nonword resulted. Insofar as a familiar schema persisted, though, it was one characterized by the "presence" of an E. That is, BAKFRY might yet be encoded as BAKERY, or MARKFT as MARKET.

Even if BAKFRY were encoded as BAKERY. though, it might yet be easier for a subject to notice the change from an $E$ to an $F$ in this case than in a nonword. A deviant letter in the familiar schema of a word might well be set off in striking relief, so that the misspelled word would be seen as a schema with correction (cf. Woodworth, 1938). Thus, there are two possibilities: the deviant letter $F$ may be assimilated into the familiar schema of the word and thereby become more difficult to detect, or the deviant letter $F$ may be contrasted with the familiar schema of the word and thereby become easier to detect.

Previous work is contradictory as to whether the familiar schema tends more to conceal (assimilation) than reveal (contrast) a deviant element. In support of the "assimilation" view, Postman, Bruner, and Walk (1951) found that a mirror-image letter was perceived as reversed relatively more slowly when embedded in a word rather than a nonword. Earhard (1968), though, found that the presence or absence of an unusually thin letter in a briefly exposed item could be discriminated about equally well in words and nonwords. In support of the "contrast" view, Snyder (1970) found better recognition of type of letter mutilation, given correct letter identification, for more familiar letter sequences. Snyder's mutilation typically involved deleting a line segment. Pollatsek, Well, and Schindler (1975) found that a physical difference between two items involving a case change was detected faster for words (e.g., leAF-lEAF) than for nonwords (e.g., snKI-sNKI). In this case, however, both versions of the word were yet words, which, for all the strangeness due to their case alternation, ought nevertheless to be more familiar than nonwords.

\section{Method}

The same method was used as in Experiment III, except that only common words and their corresponding nonwords were presented, and the items missing an $E$ were obtained by "mutilating" items which originally had contained an E (i.e.. by changing the $E$ to an $F$ ), rather than by substituting items which 
contained no E. Subjects were told that whenever an E did not appear in an item, an $F$ would be present, but that they ought not to look just for an F, because there would be items which contained both $\mathrm{E}$ and $\mathrm{F}$.

Subjects. Twenty Ohio State University undergraduates participated as subjects as part of a course requirement.

\section{Results}

The subjects again searched significantly faster through word than through nonword lists, 540 vs. $609 \mathrm{msec} /$ item, $\mathrm{F}(1,19)=66.41, \mathrm{p}<.001, \mathrm{MS}_{\mathrm{e}}=$ 1,421.31. The mean error rate was higher for words than nonwords, $3.4 \%$ vs. $1.6 \%$, but not to a significant extent, $\mathrm{F}(1,19)=3.16, \mathrm{p}<.10, \mathrm{MS}_{\mathrm{e}}=$ 22.29. The Word-Nonword by Target PresenceAbsence interaction, however, was significant on error rate, $\mathrm{F}(1,19)=8.72, \mathrm{p}<.01, \mathrm{MS}_{\mathrm{e}}=23.11$; separate analyses revealed a nonsignificant difference between words and nonwords on trials in which the critical item was absent (i.e., all 30 items contained an E), and a significantly higher error rate for words than nonwords on trials in which the critical item was present, $6.1 \%$ vs. $1.0 \%, F(1,19)=7.91, \mathrm{p}<.025$. $\mathrm{MS}_{\mathrm{e}}=32.24$. Thus, the subjects were much more likely to overlook the substitution of an $F$ for an $E$ in the case of words than in the case of nonwords. There was little change in the pattern of results on either search time (see Table 4) or error rate (see Table 5) across the five trial blocks.

\section{Discussion}

The fact that the deletion of a lower line segment, which changed an $E$ to an $F$, was detected less consistently in words than in nonwords indicates that the letter features in words were not attended to or "seen" as clearly as those in nonwords. Thus, the results support the notion of "proofreader's errors." In the case of words, the letter F, which replaced the $\mathrm{E}$, might actually have changed its appearance, assimilating towards that of an $\mathrm{E}$ and acquiring a lower limb (cf. Krueger, 1975), or the F might simply have gone unnoticed because adults typically sample only some of the letters in a familiar word (cf. Hochberg, 1970a, b; Robinson, 1969). The faster

Table 5

Mean Percentage Error Rate in Experiment IV, by Trial Block

\begin{tabular}{crc}
\hline Block & Words & Nonwords \\
\hline Critical Item Present & & \\
1 & 12.5 & 6.7 \\
2 & 5.0 & .0 \\
3 & 1.7 & .0 \\
4 & 5.0 & .0 \\
5 & 6.6 & .0 \\
Critical Item Absent & & \\
1 & 1.7 & 1.7 \\
2 & 1.7 & 3.4 \\
3 & .0 & 3.3 \\
4 & .0 & .0 \\
5 & .0 & .0 \\
\hline
\end{tabular}

search through words suggests that words suffered from "too little" rather than "too much" processing, that is, that subjects simply failed to notice the F, rather than changing its appearance to that of an $E$.

Subjects could have searched faster through words than through nonwords either because the discrepant letter was more conspicuous in words ("it stood out in the words and was easier to notice," "I just knew the E should be there; if not it caught my eye," as some subjects reported after the session) or because the critical item as a whole was more conspicuous in a word ("when an $E$ was gone in a word you knew automatically that that was wrong," and "it just didn't look right on the words"). The words had an additional advantage over the nonwords in that the subject actually did not need to locate the discrepant letter, but merely to determine whether the item was a word or not. Few subjects made conscious use of such a strategem, however, because only three $(15 \%)$ subjects answered "yes" afterwards when specifically asked: "Did you ever look for a word that did not contain an E simply by looking for an item that was not a word?" That the discrepant letter or item actually did not stand out as much on words as it might have seemed to subjects, however, is indicated by the higher error rate on words than on nonwords.

That the subjects generally did not develop complex strategies, such as looking for a nonword on word lists, also is indicated by the fact that the difference between word and nonword lists on speed and accuracy remained virtually constant across the five trial blocks. The subjects were either unable or unwilling to reduce their relatively higher error rate on words by reducing their relatively faster search through word lists.

One explanation as to why letter mutilations were less easily discerned in familiar letter sequences in the present study, but more easily discerned in familiar letter sequences in Snyder's (1970) study, is that Snyder's tachistoscopic procedure ensured that subjects would attend for the same duration to the individual words and nonwords shown. The visual search procedure used in the present study, by contrast, allows the subjects to speed up on word lists and thus give less attention to each particular item being processed. The discrepancy between the present results and Snyder's also might be due to the fact that the deleted segment varied in size, placement, and letter affected for Snyder, but not for the present study. The mutilation in the present study was quite small and occurred at the bottom of a letter, which may well have contributed to its being assimilated to the expected $E$ or perhaps even overlooked entirely in the word. There may be some optimal level of mutilation in a word, such that the mutilation is not too large to destroy the integrity of the familiar schema, yet is large enough to avoid assimilation and to force itself upon our attention, in part due to its novelty within the familiar schema. 


\section{REFERENCES}

EARHARD. B. Perception and retention of familiar and unfamiliar material. Journal of Experimental Psychology. 1968. 76. 584-595.

Gibson, E. J., Tenney. Y. J., Barron, R. W., \& Zaslow, M. The effect of orthographic structure on letter search. Perception \& Psychophvsics, 1972, 11, 183-186.

Hochberg, J. Attention, organization, and consciousness. In D. I. Mostofsky (Ed.). Attention: Contemporary theory and analysis. New York: Appleton-Century-Crofts. 1970. Pp. 99-124. (a)

Hochberg, J. Components of literacy: Speculations and exploratory research. In H. Levin \& J. P. Williams (Eds.), Basic studies in reading. New York: Basic Books. 1970. Pp. 74-89. (b)

Hock. H. S., Gordon, G. P., \& Marcus, N. Individual differences in the detection of embedded figures. Perception \& Psychophysics, 1974, 15, 47-52.

KrUeger. L. E. Search time in a redundant visual display. Journal of Experimental Psychology, 1970, 83, 391-399.

KRUEGER. L. E. Familiarity effects in visual information processing. Psychological Bulletin, 1975, 82. 949-974.

Krueger. L. E.. Keen, R. H., \& Rublevich, B. Letter search through words and nonwords by adults and fourthgrade children. Journal of Experimental Psychology, 1974, 102, 845-849.

NeISSER. U. Decision-time without reaction-time: Experiments in visual scanning. American Joumal of Psychology, 1963, 76. 376-385.
NeIsser, U. Visual search. Scientific American, June 1964, 210. 94-102.

Neisser. U., Novick, R., \& LAZAR, R. Searching for ten targets simultaneously. Perceptual and Motor Skills, 1963, 17, 955-961.

Pachella. R. G. The interpretation of reaction time in information-processing research. In B. H. Kantowitz (Ed.), Human information processing. Tutorials in performance and cognition. Potomac, Md: Erlbaum, 1974. Pp. 41-82.

Pollatsek. A., Well, A. D., \& Schindler, R. M. Familiarity affects visual processing of words. Journal of Experimental Psychology: Human Perception \& Performance, 1975. 1. 328-338.

Postman, L., Bruner, J. S., \& Walk, R. D. The perception of error. British Journal of Psychology, 1951, 42, 1-10.

Robinson, J. S. Familiar patterns are no easier to see than novel ones. American Journal of Psychology, 1969, 82, 513-522. SNYDER. C. R. R. Familiarity and processes of visual search. Unpublished MA thesis. University of Oregon, 1970.

SN YDER, C. R. R. Individual differences in imagery and thought. Unpublished PhD dissertation, University of Oregon, 1972.

Woodworth, R. S. Experimental psychology. New York: Holt, 1938.

(Received for publication May 1, 1975; revision received July 31,1975 .) 